\title{
Migrating art: A research design to support refugees' recovery from trauma - a pilot study
}

Emma Rose (Corresponding author)

Lancaster Institute for Contemporary Arts, LICA Building, Lancaster University, LA1 4YW, United Kingdom

Email: e.rose@lancs.ac.uk Tel: +44 1524593179

Amanda Bingley

Division of Health Research, Furness College, Lancaster University, LA1 4YG, United Kingdom Email: a.bingley@lancs.ac.uk Tel: +44 1524592718

\section{Introduction}

There is an urgent need to understand the effects of forced displacement, so that policies can develop in ways that take account of both immediate and long term needs of refugees, and contribute to their resilience building. This could help mitigate the impact of the psychological and social stresses experienced by refugees during and after migration. Whilst recognizing that geopolitical, economic and cultural influences affect the health of refugees, it is important to explore new possibilities for emotional health promotion research, practice and education in refugeereceiving societies. The psychological and social stresses experienced by refugees during migration can double the prevalence of severe disorders (psychosis, severe depression and disabling anxiety, and PTSD), and increase the prevalence of mild to moderate mental disorders from $10 \%$ to $15-20 \%$, according to the World Health Organisation (WHO/UNHCR 2015). A study undertaken by Fazel, Wheeler, Danesh (2005) indicates refugees resettled in western countries could be about ten times more likely to have post-traumatic stress disorder than age-matched general populations in those countries. Even if, as suggested by Fassin and d'Halluin (2007: 306), Watters and Ingleby (2004: 550), and Watters (2001: 1710), the prevalence of PTSD is over-estimated (for instrumental purposes, in mobilising resources, welfare, or asylum status), there is evidence of substantially increased prevalence of mental health disorders for refugees (Fazel and Stein, 2002: 336; Fazel, et al. 2012: 255).

This pilot study was designed to enable researchers to explore how a participatory arts intervention can best be designed to benefit refugees who have experienced human rights abuses. It was undertaken in the North West of England, UK, with a charity supporting pre and post-natal women migrants, refugees and asylum seekers who are victims of rape, trafficking, sexual violence, domestic 
servitude, and other forms of gender based violence and human rights abuses. Ethical issues were central to the research design, its methods and delivery at all stages of the project. The researchers drew upon previous experience of working with vulnerable groups in participatory arts projects, and were guided by the University Ethics Committee in limiting the potential of harm to the participating group and the researchers. A key concern was to ensure participants' psychological wellbeing throughout the project's duration and not to cause more harm or to re-traumatize participants. For this reason landscapes associated with safety, and the notion of a 'safe-haven' with positive associations was emphasized. The provision of a safe space for the intervention to take place, and preservation of the anonymity and safety of participants were other important factors considered in design and delivery, prompting various challenges that were addressed and are discussed later in the article.

The research is focused on the activity of painting landscapes by re-imagining places that elicit positive feelings; including place(s) re-imagined that may be part of their experience of a 'safehaven' or a journey towards safety. With this focus the study seeks to identify the beneficial engagement of individuals in the participatory arts intervention, and in exploring what types of landscapes have emotional meaning and the significance of their re-imagination, indicate how participatory arts offer a visual language for communication and expression - giving voice to a marginalized group. It aims to assess the research design and problems associated with undertaking the research, to inform a larger more conclusive research study designed to evaluate the effectiveness of the approach in contributing to refugees' recovery and transition.

It is important to emphasise, as discussed later in the paper, that the intervention is within a context of participatory arts and not art therapy. As such the pilot draws on practices in participatory arts that create a safe space for people to engage in art as a supportive group activity (Cameron et al., 2012). Through the art activity, participants are invited to create a place with which they have strong positive feelings; in this case they painted real or imagined landscapes they might visualize during periods of stress or distress.

In this article we first contextualise the study within relevant therapeutic landscape literature (Gesler, 1993; Glannon, 2004; Perriam, 2015; Williams, 2007) and participatory arts interventions, to map key theories and concepts underpinning the research area. Second, the research methods are explained including the study design and analysis of its effectiveness. Finally, an examination of visual material produced by participants seeks to better understand what spaces and places emerge, 
with a view to assessing the programme's potential to contribute to recovery and transition in a further project.

\section{Therapeutic Landscapes}

The theory of therapeutic landscapes (Gesler, 1993, Williams, 2007) supports an expanded field of research exploring how different types of landscape can benefit health and wellbeing. Drawing from Gesler's original therapeutic landscape concept, subsequent research has developed the concept more broadly than spiritual sites and health settings, to environments that include physical, psychological, social and symbolic spaces associated with healing. Healing as a concept is intrinsically connected to therapeutic landscapes for Perriam (2015) who examines the relationship between place, spirituality and healing. She explores healing as a search for wholeness, implying a fragmented self can be mended, or re-formed as a healthy, whole body. Healing in this sense is not a cure, but alleviation, a possible reduction in the severity of symptoms and improvement in the quality of life (Glannon, 2004). Thus, both Perriam and Glannon establish a connection between belief and place to catalyse healing and promote recovery.

Imagining beneficial places has been the subject of research by several authors in geographies of wellbeing (Williams, 1998; Rose, 2012; 2016). Building on the work of Gestaldo et al. (2004), Rose (2012) explores the notion of landscapes of the mind to emphasize the benefits of imaginary or metaphoric representations of landscape, including artistic representations, to improve wellbeing. In re-imagining landscapes with metaphorical associations, she suggests the individual is able to identify and attenuate intense emotion and traumatic memory, a key component of engendering change and recovery. The work of Gestaldo et al. (2004) is relevant in prompting the researchers to consider aligning the concept of therapeutic landscapes with experiences of migration and strategies to improve mental wellbeing through art. Gestaldo et al. explore how personalized place-related memories, particularly those associated with 'home' and safety evoked through memory, narrative and artistic representation, provide migrants with coping strategies beneficial to mental wellbeing.

Thus, the pilot created a space for participants to explore imagined landscapes through art, a process the researchers anticipated could have potential benefits for wellbeing (Marxen, 2009; Bingley, 2012). The premise suggests that re-imagined representations of landscape, realized as physical representations as paintings on canvas, can provide participants with a mental and physical place that may be visited in times of stress, and thus contribute to healing. The pilot study explores these ideas, and the potential of an arts programme to contribute positively to an individual's 
connection to a sense of self in a different environment, as a process of adaptation and transition, and also a healing experience.

\section{Participatory Arts}

Over the last ten years the field of art and design for health has grown substantially, as evidenced by the emergence of specialist academic journals and conferences worldwide. Recognition that benefits can accrue from engagement in the arts has fostered greater cultural engagement activities both broadly in public health (Cameron et al. 2013) and more specifically in areas such as dementia, mental health, old age, social deprivation, obesity, and more recently refugees (Andemicael, 2011). However, policy-makers, health professionals, and funding organisations have been constrained by limited research underpinning what is intuitively understood by those in the sector (Clift, 2012) and research responding to this focus is growing. Arts Council England's (ACE, 2014) evidence review draws on recent UK reports to demonstrate that participation in the arts has positive physical and psychological impacts on health for a broad range of groups. Gordon-Nesbit (2015) explores the longitudinal relationship between arts engagement and health with a scoping review in the UK and internationally across English-language studies. The evidence-base, drawn from fifteen studies, collectively suggests that arts engagement has a beneficial impact on health over time.

The pilot study is an intervention in participatory arts but it is useful here to expand on the distinction between participatory arts and the practise of art therapy. In art therapy the focus is on the art as therapy. Individuals or a group are facilitated by a trained psychotherapist to use art materials in the context of a therapeutic space as an empathetic 'therapeutic encounter' in selfreflection, development of self-awareness, and self-expression (Wood, 1998: 1). In contrast, participatory arts projects are not primarily designed to be a therapeutic encounter in a psychotherapeutic context. Instead a participatory arts project is designed as a creative space for people to engage in various arts activities (music, art, dance etc.). This may be as a means to perhaps promote the benefits of singing in community engagement; arts to support young people with mental health problems; or for older people to promote healthy ageing and wellbeing, reduce social isolation, or as a community event to foster shared, creative activities across different ages. Thus, mental health professionals are interested in the use of participatory arts as an adjunctive intervention to support their clients (Stickley, 2010). However, although people taking part may report benefits to their mental health and wellbeing (see Clift, 2012; Cameron et al. 2013) participatory arts are not regarded as therapy and do not necessarily require the involvement of a 
psychologist or psychotherapist. As Bingley (2003) notes a similar distinction must be made by researchers using participatory arts in research and art as therapy.

In this context it is unsurprising that the number of organisations supporting displaced people through participatory arts and art therapy have grown over the last decade. The international challenge presented by an unprecedented number of refugees, an expected 3 million in Europe by 2017 (Juncker, 2015), has coincided with the increasing recognition of the role of art and art therapy in supporting refugees to cope with trauma, rehabilitation, and healing; contributing to this interest. Research evaluating the impact of participatory art interventions with refugee populations is a limited, though growing, area of research. The Office of the United Nations High Commissioner for Refugees (UNHCR) has publicised ways in which refugees' involvement in artistic activity can play a powerful positive role in their ability to survive physically, emotionally and spiritually. However, impacts are still largely anecdotal (Andemicael, 2011). As Andemicael suggests, more focused research is needed on existing programs and artistic activities, in order to evaluate their current and potential benefits, and to learn what activities are successful or otherwise (2011: 6).

\section{Methods}

The pilot study seeks to identify the beneficial engagement of individuals in the participatory arts intervention, and in exploring what types of landscapes have emotional meaning and the significance of their re-imagination, indicate how participatory arts offer a visual language for communication and expression. It aims to assess the research design and problems associated with undertaking the research, and to inform a larger more conclusive research study seeking to evaluate the effectiveness of the approach in contributing to refugees' recovery and transition.

Thus the pilot set out to explore the role of painting re-imagined places associated with actual or imagined safe-havens from the women's homeland or their journey; to assess the potential of the approach to contribute to their sense of recovery and transition; and to examine research design, methodology and data collection methods. Methods of participatory action research (PAR) were employed to promote collaboration between stakeholders and to foster a supportive and empowering environment (McIntyre, 2008). The research design drew upon Mclntyre's approach to PAR and incorporated a reflexive process throughout each stage of the project, offering the opportunity for participants and researchers to be involved with, and contribute to, the different aspects of the investigation through exploration, action, reflection and evaluation. The researchers, charity workers and participants worked collaboratively to explore the challenges encountered in 
delivering the intervention and to assess its overall effectiveness. Qualitative research methods were employed in observational and visual data collection, workshop discussions, participant notebooks, and an end of project group discussion. These approaches are consistent with PAR as the methods encourage and facilitate a shared exploration and expression of people's subjective experiences, ideas, and memories. In line with PAR we created space for discussions during the project between researchers, participants and charity workers with the aim of enabling shared learning, implementation of agreed adaptations to the programme, and reflection on the impact of the activities for the participants after each session.

To preserve the participants' anonymity and their safety, visual data collection in the form of photographs were limited to paintings or group images that avoided the women's faces, or any aspect of them that may be recognizable. Participants were invited to share their thoughts about their artwork with the research team, who as part of the data analysis interpreted how participants engaged with their art and the content of paintings. The data were analyzed using visual data analysis methods exploring the content and theme of the paintings (Rose, 2013). The content was identified in terms of the various elements depicted (items, buildings, type of landscape, presence of people and/or wildlife or flowers and so on). Then, drawing on reflections with participants (shared thoughts or written notes about their paintings), the key themes of each painting were identified and interpreted by the team. In this way, the researchers aimed to better understand the relationship between the experience of migration, remembered landscapes and how these were expressed in participants' artwork.

Following ethical approval from the University Research Ethics Committee, initially recruitment was by the charity workers who publicized the workshop at the regular session at the centre, distributed flyers to all those interested and provided paper copies of information appropriate for those with English as a second language. Where needed, for women with limited English language, the charity workers aimed to provide access to on-site interpreters. Researchers also sought recruitment at the start of the project by talking to the women visiting the centre, and identifying those whose other needs (support with children, housing or asylum issues) were not so pressing that they could devote their time to the workshop.

\section{Research design: intention and adaptation}

Navigating the study's intentions, whilst having to adapt to circumstances, was continuous throughout delivery of the programme. We examine this adaptation in order to understand the 
project's challenges, and to provide insights into designing future research in terms of improving the planning and process of the workshops and the likely benefits for participants.

Introducing the intervention in an already busy centre presented challenges, especially as the women attending were not there every week, and had greater concerns about accessing advice services, feeding themselves and their children, and maintaining links with their social networks. Recognising this challenge in the first session led the research team to adapt the intervention as open, rather than a sequence, and women were free to join in as they liked each morning and across all three sessions, each session lasting 90 minutes.

From the start of the introductory session the women quickly started to try out the paints and brushes on the group roll of paper, and were invited to paint whatever landscape or place they felt that had some special significance in relation to positive feelings of safety. These were generally depictions of places and spaces, sometimes populated with people and animals. The group created a five-metre length mural representing individual scenes, reflecting the diverse homelands of the participants, or significant journeys they had undertaken, or places where they imagined they would like to live. During the activity each participant discussed their paintings with members of the research team. At the end of the session the mural was cut into the different contributions for the women and children to take home. The women invested their subject-matter with the same degree of personal significance in this warm-up mural as in the next core session.

Session two, planned as a core workshop, was adapted to ensure that women could join in even if they had not attended the introduction. The theme was explained on an individual basis, with the practical demonstration of painting repeated for those who had missed the first session. Participants had the opportunity to make several paintings on canvases of different sizes, so they could experiment, explore different subject matters, 'go wrong', make mistakes and start again. This also meant children could be involved in painting with their mothers, either contributing to or making their own painting. As the participatory group was small it was encouraging for more people present to be painting, and some research team members painted alongside participants; this was valued and helped in the exchange of technical knowledge and to balance the relationship between participants and organizers. It was also consistent with the collaborative PAR model seeking the empowerment of participants. After the session the paintings were photographed, and the paintings printed as a record of participant's work, in addition to their canvas, that they could take home. Researchers were able to discuss the prints with the women. This helped the team better 
understand the work produced and assess the impact of the activity. No audio-recordings of discussions were taken as planned, only written field notes as researchers felt this would disrupt normal activity, and potentially compromise the women's privacy, and correspondingly their sense of safety in the workshop. Participants were also offered a notebook to record their thoughts or conversations with others between sessions about their painting. However, only three women took a notebook (none took them home), to share some thoughts after session, and handing them back to the researchers.

In the third, final session, all those joining the group were free to paint any subject they liked. The team talked with group members individually, as it was clear the women were not confident talking in a group session. They talked about their experience of the project, what had or not been helpful, and whether they would like this kind of art activity to be provided in the centre.

\section{Findings}

Nine women took part from seven nationalities: Albania, Ghana, Iraqi Kurdistan, Iraq, Iran, Malawi, and Turkey. With one or two exceptions, the majority had little experience of painting, and none had used acrylic paint on canvas. Technical demonstrations were appreciated and enabled participants to approach the painting process without too much concern for accuracy in representation. The approach appeared to help participants' confidence in handling the art materials. In this way women were able to depict subjects in ways that were largely impressionistic, using colour and shape for expressive purpose.

Of the 19 paintings produced the subject-matter is predominately of natural landscapes $(N=18)$, many containing a solitary building, described as a house in which the participant had lived in her homeland $(\mathrm{N}=10)$. The landscapes feature fields and crops, flowers and trees, grass and sky, and often the sun. A good proportion contain flying birds $(\mathrm{N}=8)$. Two of the homeland houses also depict family members, in both cases this was the woman herself with children, in one case also with her husband. Paintings depicting natural landscapes devoid of buildings or people $(\mathrm{N}=7)$ represent mountains, rivers, and seascapes connected to journeys across the sea, or towards far off mountains. There were also two abstract interpretations where colour or pattern was associated with remembered places.

\section{Re-imagining landscapes: homeland houses and safe-haven journeys}


The study set out to explore whether re-imagining landscapes has potential to contribute to the women's sense of recovery and transition. Two main themes were identified, characterised here as homeland houses and safe haven journeys which depict natural landscapes that seem quite idealized, or at least selectively re-imagined. For example, the paintings include verdant green foliage, blue skies, and red ripe fruit and colourful flowers, in some cases where these landscapes are more often associated with drier, browner, less fertile pastures. A yellow sun features in most of the paintings which, in the context of the North West of England where cloudy, dull skies are characteristic, suggests the otherness of their homeland, possibly serving as a marker of difference. With only one or two exceptions none of the paintings included vehicles, farm machinery, outbuildings, waste bins, roads and sign posts. Although none of the women referred to these omissions, it is possible that this process served to filter out unwanted elements to reinforce positive elements, and potentially to enhance emotional attachment. In the next section we explore how emotional attachment is connected to safety, and in considering the paintings gain insights into whether they might help recovery and transition.

Participants mostly described the place as re-imagined and a safe place with which they have feelings of positive attachment. In one case an idealized homeland is walled off from the remaining landscape, and the woman described how much the place means to her but that she can never go back. The theme of never being able to physically return was repeated many times in discussion, and although associated with sadness, the women were pleased, and often proud, to depict such places and talk about them to others.

For another participant, originally from Turkey, safety is represented by her homeland house, architecturally structured to enable the viewer to look inside, where a vase of red flowers takes central position. Outside the trees are full of fruit; and standing together are a woman, a boy holding her hand, a small girl, and a man, who gives the woman a bunch of flowers - like those depicted inside the house. A very large bird sits on the roof of the house and another large bird followed by two smaller birds fly away over the heads of the family. The participant said the painting shows her family and that they were very happy, but now she and her children can never go back.

INSERT Figure 1: Painter from Turkey, 2016, Acrylic on canvas, 457 x 356 mm.

For another woman, originally from Albania, safety is represented by a town at dusk, comprised of dark grey, cube-like buildings, lights coming from many small apartments. There are no people on the streets, signs, or streetlights. The buildings have flat roofs, except for the church in the centre of 
town that has a steeple and a cross. The sun is setting in a darkening sky. An apartment building to the left is presented in some detail and in perspective. To the right of the painting another apartment depicts open curtains in a window, and a woman is looking out into the night. The painting represents the ten minutes each evening when she could leave the building to look at the sun setting. She explained that she had to stay inside the room for nine months before she could leave for a place of safety. The building on the right is a larger version of the building on the left, in order that she could show herself in the house looking out.

INSERT Figure 2: Painter from Albania, 2016, Acrylic on canvas, 457 x 356 mm.

Countering assumptions of what the researchers thought of as a safe haven, a woman originally from Iran depicts the open sea as a place of safety, explaining that the sea was for her safer than the land. In the context of the many refugee lives lost at sea this highlights the relativity of safety. For this woman, whether escaping war, conflict, poverty, persecution or human rights abuses the risky place is considered safer, and the sea symbolic of a safe-haven.

INSERT Figure 3: Painter from Iran, 2016, Acrylic on canvas, 297 x $210 \mathrm{~mm}$.

A participant originally from Ghana, imagined a place of safety in England to which she would like to go. The painting portrays undulating hills, blue sky and sunshine, four red birds flying, and five woolly black and white sheep jump across the hilltops. The woman said she has seen places like it out of the window on a train in England. She likes the idea of keeping sheep. The woman has reached a place of relative safety in England. However, she imagines living in a rural location with her child, rather than the inner city location in the North West of England, renowned for its social deprivation and decline, where poor housing and multi-let properties predominate, and access to rural, natural spaces is difficult. In this context it is worth noting the substantial literature exploring green space access versus urban built environments as potential determinants of health and health inequalities (see for example Gelormino, 2015; Melis et al., 2015; Macintyre et al., 2008). Results from the study undertaken by Melis et al., in agreement with the other literature, suggest that people who spend longer in the built environment and experience limited access to green spaces are more prone to mental health disorders and increased use of anti-depressants.

INSERT Figure 4: Painter from Ghana, 2016, Acrylic on canvas, 457 x 356 mm. 
That the majority of paintings depict natural landscapes seems significant. The researchers were careful to encourage participants to paint an imagined place of safety, and to emphasize the range of landscapes they might consider, for example, urban, rural, natural or built whether a garden, bedroom, city or lake. Within the therapeutic landscape literature, research demonstrates that a connection with nature in natural landscapes, or green space, either urban or rural, is perceived as beneficial, even vital for well-being (Andrews, 2002; Johnson et al., 2005; Neilsen \& Hansen, 2007). However, it should be noted that not all encounters with natural landscapes are therapeutic; there are places and spaces where people have negative or distressing associations involving feelings of risk, fear, or exclusion (Andrews and Holmes, 2007; Sperling and Decker, 2007; Curtis, 2010; Milligan and Bingley, 2007; Ward-Thompson et al., 2004). The research indicates that when people connect positively to a natural landscape it can reduce stress and depression, and elicit positive psychological and physiological responses.

The therapeutic potential of natural landscapes has been described as a connection between landscape as a restorative space and emotional well-being (Ulrich, 1979; Kaplan and Talbot, 1983; Hartig et al., 1996, 2003; Cooper-Marcus and Barnes, 1999). Kaplan \& Kaplan (1989) explore the restorative function of natural landscapes, using a broad understanding of the term to examine the everyday alongside conventional landscape settings. They suggest that such environments have a 'soft fascination' with potential to provide an aesthetic experience that invites attention but leaves room for reflection, a dynamic restorative to mental wellbeing.

\section{Research design}

Examination of research design, methodology and data collection methods reveal several challenges that would need to be addressed in a future project seeking more conclusive research. Core issues concern the dynamics of the space used for the art workshop; technical expertise with the materials of painting; the lack of sufficient English language for participants; and the need for interpreters throughout the workshops.

In terms of setting up a safe workshop space, a separate room was used away from the main hall, which created a relatively quiet place to work. To join the group the women either chose to leave their children with one of the other mothers (or with one of the research team) in the main hall, or brought their children to join the other participants. Either option meant that for some women concern about their children was distracting and they were less able to focus on the art activity. It was also quite daunting for the women having to locate the separate room from the main hall. The 
charity workers pre-warned researchers that the women would have anxieties associated with official paperwork, as many were experiencing unresolved asylum status. Indeed when the women entered the workshop space they expected to engage in the painting activity and not to be involved in paperwork associated with ethical requirements. Thus, it was necessary to reassure them through the painting activity and through our interaction that it was a safe creative place. Ethical requirements were met, but required considerable time in individual discussions.

Individual and group discussions revealed that some participants felt very unconfident using art materials. Given the project was scheduled for only three sessions and the group attendance fluctuated from week to week, it was difficult to familiarize everyone equally with the art materials and painting process. One or two women explained that they would have liked longer to learn how to use the paints and wished they were better able to express their story in the paintings. One solution may be to run a small demonstration art group in the main hall as an introduction to working methods and materials, alongside completion of any paperwork, and only move to a separate space once the group was more established.

Providing sufficient interpreters was found to be essential. Given the transience of the centre attendance it was not possible to match the number of languages spoken in the group with interpreters. For example, an Arabic or African translator did not cover the two or three different Arabic or African languages spoken by participants. Usually when a language was a barrier someone else in the centre could translate, though not for all participants. Matching participants with interpreters earlier in the programme was found essential, and to provide research information visually rather than in text form.

In terms of the research design, ethical considerations given to supporting the women and the researchers with debriefing sessions, and liaison with the charity facilitators seemed to work well, though it was essential to recognise the need for time to talk with the participants so they felt clear about the project and what was involved if they took part. The women were in a relatively safe environment, but needed to prioritize accessing a range of services over attendance at the programme. The art activities would work better for those attending regularly for the purposes of a further intervention.

\section{Concluding Comments}


The pilot draws out some of the links between the conceptualisation of therapeutic landscapes and its application in practice with the activity of painting. Participants' overwhelming interest to depict natural landscapes is examined in the context of substantial research indicating beneficial impacts accrue from positive encounter with natural landscapes. Understanding the activity within this framework suggests the women's re-imagining of nature in the context of painting can be in some way self-healing, and potentially restorative.

Connected with this, the study explores how participants' depictions of nature, developed from selective re-imagining enhance this process. In giving emphasis to re-imagining place with positive emotional attachment, places idealized in participant's minds were accentuated through editing out less ideal elements, emphasizing the 'natural'. In this context, it should be noted the activity of painting may be influenced by different cultural associations of natural landscape with aesthetic representation, reinforcing nature as a culturally legitimate space for emotional attachment and representation. The study offers insights into what meanings landscape in the different physical, mental or representational forms may have for displaced people and those who move across national boundaries. These findings help to identify the ways in which space and place have emotional significance for refugees in terms of the past, loss and displacement, and hope for the future. This is highlighted, poignantly, in the context of their current lives in the inner city location in the North West of England, where there is a lack of green space or access to natural landscapes.

The study seeks to identify the beneficial engagement of individuals in the participatory arts intervention. This is illuminated in connection with exploring how the intervention might support the women's transition. The programme emphasises the depiction of places associated with safety and the findings suggest depicting a safe-haven enabled the women to connect their past with positive emotions realized in the present, and to realize these in a visual form, expressed to themselves and to others in the paintings, and in conversations. This may help to counteract isolation and potentially contribute to wellbeing, as well as offer a chance to share their paintings with each other, the research team and charity facilitators. Imagery shared by the women, of houses, crops, sunshine, water and mountains promoted conversation; the paintings affording a bridge between their identity then and now. The engagement of the women in the workshops, and their comments in discussion, indicated that their experience within the participatory programme seemed rewarding and thus had some potential to enhance their feelings of personal wellbeing. 
It is important to highlight the limitations of the study. The problems are documented above, noting the need for language support and interpreters, an accessible, appropriate workshop, and time to teach painting skills. The centre's transient attendance and the competing needs of the women meant only a modest number of participants were sampled, not adequately representing the target population. In addition, in implementing a process of re-imagining a safe-haven, of holding place in mind, the programme sought to explore whether this might contribute to participant's experience of retaining a place of safety that can be revisited in times of stress. The research was unable to identify whether the landscape selected for their painting might have this role. A larger and longer study would be needed to investigate this dimension.

There is a case for a further study exploring how participatory arts activities can best support refugees and their transition to a new country, and their recovery from human rights abuses. It is important to recognize the strong emotional reactions people have to spaces linked with past experiences, significant people, and events. Given the traumatic experiences of many refugees, it would not be helpful in participatory arts settings to construct activities of remembering per se, devoid of positive content. It is also the view of the researchers that in any further project, the workshops should include a psychotherapist familiar with the group who could attend the workshops for the safety of participants and to provide debriefing for the researchers.

The theme used in the pilot study is adapted from established theories of therapeutic landscapes exploring the role of place in relation to wellbeing over two decades. Connected to best practices in participatory arts, the pilot study emphasized imaginative interpretation of past, present and future places associated with safety, and did not have an expectation that participants use their life stories, or their trauma, as resources for the project. A key message from this research is the theme of reimagining as it applies to place with which individuals have strong positive and safe associations.

The conclusions drawn from this pilot study indicate how participatory arts offer a visual language for communication and expression for this vulnerable group, and the kinds of potential benefits made possible by adapting the research model for a further participatory arts intervention. The pilot study is helpful first, in identifying what challenges must be addressed when undertaking a larger more conclusive research study planned with another group of vulnerable migrants, second, in seeking to evaluate the effectiveness of the approach in contributing to refugees' recovery and transition. 


\section{References}

American Anthropological Association (AAA) (2004), 'Statement on ethnography and institutional review boards, Adopted by AAA Executive Board June 4, 2004', http://www.americananthro.org/ParticipateAndAdvocate/Content.aspx?ItemNumber=1652 Accessed 28 February 2017.

Andemicael, A. (2011), 'Positive energy: A review of the role of artistic activities in refugee camps', Office of the United Nations High Commissioner for Refugees (UNHCR), http://www.unhcr.org/4def858a9.html. Accessed 11 January 2017.

Andrews, G. J. (2002), 'Towards a more place-sensitive nursing research: An invitation to medical and health geography', Nursing Inquiry, 9: 4, pp. 221-38.

Andrews, G. J. (2004), '(Re)thinking the dynamics between healthcare and place: therapeutic geographies in treatment and care practices', Area, 36: 3, pp. 307-18.

Andrews, G. and Holmes, D. (2007), 'Gay bathhouses: The transgression of health in therapeutic places', in A. Williams (ed), Therapeutic Landscapes: The Dynamic between Place and Wellness, Lanham, MD: University Press of America, pp. 221-33.

Arts Council England, (2014), The Value of Arts and Culture to People and Society: an evidence review, http://www.artscouncil.org.uk/exploring-value-arts-and-culture/evidence-review. Accessed $10^{\text {th }}$ November 2016.

Asociatión Exil and Comissió Catalana d'Ajuda al Refugiat with British Refugee Council, Freedom from Torture, Greek Council for Refugees, ICAR Foundation, Psychosoziales Zentrum Düsseldorf, REFUGIO München, Syn-Eirmos -Babel (2015), Good Practices with Victims of Torture, http://www.centroexil.org/media/contents/actualidad/good_practices_with_victims_ of_torture.pdf. Accessed 01 March 2017.

Barnes, S. (ed) (2009), Participatory Arts with Young Refugees, London: Arts in Education, Ovalhouse Theatre, http://www.ovalhouse.com/participation/publication/participatory_arts_with_young refugees. Accessed 01 March 2017.

Bingley, A. F. (2012), 'Touching space in hurt and healing: Exploring experiences of illness and recovery through tactile art', in M. Paterson and M. Dodge (eds), Touching Space, Placing Touch, Farnham: Ashgate Publishing, pp. 71-88.

Bingley, A. F. (2003), 'In here and out there: Sensations between Self and landscape', Social \& Cultural Geography, 4: 3, pp. 329-45. 
Cameron, M., Crane, N., Ings, R., and Taylor, K. (2012), 'Promoting wellbeing through creativity: how arts and public health can learn from each other', Perspectives in Public Health, 133: 1, pp. 52-9.

Clift, S. (2012), 'Creative arts as a public health resource: Moving from practice-based research to evidence-based practice', Perspectives in Public Health, 132: 3, pp. 120-7.

Cooper-Marcus, C. and Barnes, M. (1999), Healing Gardens: Therapeutic Benefits and Design Recommendations, New York: Wiley.

Curtis, S. (2010), Space, Place and Mental Health, Farnham, UK, and Burlington, USA: Ashgate.

Fazel, M., Wheeler, J. and Danesh, J. (2005), 'Prevalence of serious mental disorder in 7000 refugees resettled in western countries: A systematic review', The Lancet, 365: 9467, pp. 1309-14.

Fazel, M. and Stein, A. (2002), 'The mental health of refugee children', Archives of Disease in Childhood, 87: 5, pp. 366-70.

Fazel, M., Reed, R.V., Panter-Brick, C. and Stein, A. (2012), 'Mental health of displaced and refugee children resettled in high-income countries: risk and protective factors', The Lancet, 379: 9812, pp. 266-82.

Fassin, D. and d'Halluin, E. (2005), 'The truth from the body: Medical certificates as ultimate evidence for asylum seekers', American Anthropologist, 107: 4, pp. 597-608.

Fassin, D. and d'Halluin, E. (2007), 'Critical evidence: The politics of trauma in French asylum policies', Ethos, 35: 3, pp. 300-29, http://onlinelibrary.wiley.com/doi/10.1525/eth.2007.35.3.300/pdf. Accessed 01 March 2017.

Gelormino, E, Melis, G, Marietta and Costa, G. (2015), 'From built environment to health inequalities: An explanatory framework based on evidence', Preventive Medicine Reports, 2, pp. 737-45, http://www.sciencedirect.com/science/article/pii/S2211335515001217. Accessed 01 March 2017.

Gesler, W. M. (1993), 'Therapeutic landscapes: theory and a case study of Epidauros, Greece', Society and Space, 11: 2, pp. 171-189.

Gesler, W. M. (1996), 'Lourdes: healing in a place of pilgrimage', Health and Place, 2: 2, pp. 95-105, http://www.sciencedirect.com/science/article/pii/1353829296000044. Accessed 01 March 2017.

Gesler, W. M. (1998), 'Bath's reputation as a healing place', in R. A. Kearns and W. M. Gesler (eds), Putting Health into Place, Syracuse: Syracuse University Press, pp. 17-35. 
Gestaldo, D., Andrews, A. and Khanlou, N. (2004), 'Therapeutic landscapes of the mind:theorizing some intersections between health geography, health promotion and immigration studies', Critical Public Health, 14: 2, pp. 157-76.

Glannon, W. (2004), 'Transcendence and healing', Medical Humanities, 30: 2, pp.70-3.

Gordon-Nesbitt, R. (2015), 'Exploring the longitudinal relationship between arts engagement and health', Manchester: Arts for Health, Manchester Metropolitan University, http://www.artsforhealth.org/research/artsengagementandhealth/ArtsEngagementandHeal th.pdf. Accessed 01 March 2017.

Hartig, T., Böök, A., Garvill, J., Olsson, T. and Gärling, T. (1996), 'Environmental influences on psychological restoration', Scandinavian Journal of Psychology, 37: 4, pp. 378-93.

Hartig, T., Evans, G.W., Jamner, L.D., Davis, D.S. and Gärling, T. (2003), 'Tracking restoration in natural and urban field settings', Journal of Environmental Psychology, 23: 2, pp. 109-23.

Johnsen, S., Cloke, P. and May, J. (2005), 'Transitory spaces of care: Serving homeless people on the street', Health and Place, 11:4, pp. 323-36.

Juncker, J-C. (2015), 'State of the Union 2015', European Commission, Brussels. https://ec.europa.eu/commission/state-union-2015_en. Accessed 23 February 2017.

Kaplan, R. and Kaplan, S. (1989), The Experience of Nature: A Psychological Perspective, Cambridge; New York: Cambridge University Press, CUP Archive, https://archive.org/details/experienceofnatu00kapl. Accessed 01 March 2017.

Kaplan, S. and Talbot, J.F. (1983), 'Psychological benefits of a wilderness experience', in I. Altman and J.F. Wohlwill (eds), Behavior and the Natural Environment, New York: Plenum Press, pp. 163203.

Marxen, E. (2009), 'Therapeutic thinking in contemporary art: Or psychotherapy in the arts', The Arts in Psychotherapy, 36: 3, pp.131-39, http://www.sciencedirect.com/science/article/pii/S0197455608000993. Accessed 01 March 2017.

McIntyre, A. (2008), Participatory Action Research, in J. Van Maanen (series ed), Qualitative Research Methods, 52, London: Sage.

Macintyre S., Macdonald, L. and Ellaway A. (2008), 'Do poorer people have poorer access to local resources and facilities? The distribution of local resources by area deprivation in Glasgow, Scotland', Social Science \& Medicine, 67: 6, pp. 900-14.

Melis, G., Gelormino, E., Marra, G., Ferracin, E. and Costa, G. (2015), 'The effects of the urban built environment on mental health: A cohort study in a large northern Italian city', International Journal of Environmental Research and Public Health, 12: 11, pp. 14898-915. 
Milligan, C., Bingley, A. F. (2007), 'Restorative places or scary spaces? The impact of woodland on the mental well-being of young adults', Health \& Place, 13:4, pp. 799-811.

Nielsen, T.S. and Hansen, K.B. (2007), 'Do green areas affect health? Results from a Danish survey on the use of green areas and health indicators', Health \& Place, 13:4, pp. 839-50.

Perriam, G. (2015), 'Sacred spaces, healing places: Therapeutic landscapes of spiritual significance', Journal of Medical Humanities, 36: 1, pp. 19-33.

Rose, E. (2012), 'Encountering place: A psychoanalytic approach for understanding how therapeutic landscapes benefit health and wellbeing', Health \& Place, 18: 6, pp. 1381-87.

Rose, E. and Lonsdale, S. (2016), 'Painting place: Re-imagining landscapes for older people's subjective wellbeing', Health \& Place, 40, pp. 58-65, http://www.sciencedirect.com/science/article/pii/S1353829216300491. Accessed 01 March 2017.

Rose, G. (2013), Visual Methodologies: An Introduction to Researching with Visual Materials, 3rd ed., London: Sage.

Sperling, J.M. and Decker, J.F. (2007), 'The therapeutic landscapes of the Kaqchikel of San Lucas Toliman, Guatemala', in A. Williams (ed), Therapeutic Landscapes, Aldershot, England; Burlington, VT: Ashgate, p. 233-54.

Stickley T. (2010) 'Does prescribing participation in arts help to promote recovery for mental health clients?', Nursing Times, 106: 18, pp.18-20.

Ulrich, R.S. (1979), 'Visual landscapes and psychological wellbeing', Landscape Research, 4: 1, pp. $17-23$.

Ward-Thompson, C., Aspinall, P., Bell, S., Findlay, C., Wherrett, J. and Travlou, P. (2004), Openspace and Social Inclusion: Local Woodland Use in Central Scotland, Edinburgh: Forestry Commission, http://www.openspace.eca.ed.ac.uk/wpcontent/uploads/2015/10/Open-Space-and-Social-Inclusion-Local-Woodland-Use-inCentral-Scotland-research-summary.pdf. Accessed 01 March 2017.

Watters, C. (2001), 'Emerging paradigms in the mental health care of refugees', Social Science \& Medicine, 52:11, pp. 1709-18.

Watters, C. and Ingleby, D. (2004), 'Locations of care: Meeting the mental health and social care needs of refugees in Europe', International Journal of Law and Psychiatry, 27: 6, pp. 549-70.

Wood, M.J.M. (1998), 'What is art therapy?', in M.Pratt and M.J.M. Wood (eds.), Art Therapy in Palliative Care, London and New York: Routledge, pp.1-11. 
World Health Organisation and United Nations High Commissioner for Refugees (2015),

'WHO/UNHCR issue new guide on mental health in humanitarian emergencies', http://www.who.int/mediacentre/news/notes/2015/mental-health-in-emergencies/en/ . Accessed 23 February 2017.

Williams, A. (1998), 'Therapeutic landscapes in holistic medicine', Social Science \& Medicine, 46: 9, pp. 1193-1203, http://www.sciencedirect.com/science/article/pii/S027795369710048X. Accessed 01 March 2017.

Williams, A. (ed) (2007), Therapeutic Landscapes, Aldershot: Ashgate Publishing. 